\title{
Modeling of solar energy potential in Africa using an artificial neural network
}

\author{
D. A. Fadare*, I. Irimisose, A. O. Oni and A. Falana \\ Mechanical Engineering Department, University of Ibadan, P. M.B. 1, Ibadan, Oyo State, \\ Nigeria \\ *E-mail: fadareda@yahoo.com
}

\begin{abstract}
In this study, the feasibility of an artificial neural network (ANN) based model for the prediction of solar energy potential in Africa was investigated. Standard multilayered, feed-forward, backpropagation neural networks with different architecture were designed using NeuroSolutions ${ }^{\circledR}$. Geographical and meteorological data of 172 locations in Africa for the period of 22 years (19832005) were obtained from NASA geo-satellite database. The input data (geographical and meteorological parameters) to the network includes: latitude, longitude, altitude, month, mean sunshine duration, mean temperature, and relative humidity while the solar radiation intensity was used as the output of the network. The results showed that after sufficient training sessions, the predicted and the actual values of solar energy potential had Mean Square Errors (MSE) that ranged between $0.002-0.004$, thus suggesting a high reliability of the model for evaluation of solar radiation in locations where solar radiation data are not available in Africa. The predicted and actual values of solar energy potential were given in form of monthly maps. The solar radiation potential (actual and ANN predicted) in northern Africa (region above the equator) and the southern Africa (region below the equator) for the period of April - September ranged respectively from $5.0-7.5$ and $3.5-5.5 \mathrm{~kW} \mathrm{~h} / \mathrm{m}^{2} /$ day while for the period of October - March ranged respectively from $2.5-5.5$ and $5.5-7.5 \mathrm{~kW} \mathrm{~h} / \mathrm{m}^{2} /$ day. This study has shown that ANNbased model can accurately predict solar radiation potential in Africa.
\end{abstract}

Keywords: Artificial neural network, solar radiation, modeling, renewable energy, Africa

\section{INTRODUCTION}

Many countries in Africa are faced with immense energy challenges, characterized by low rates of access to electricity, irregularities and a general shortage in electricity supply. Solar energy provides African governments with the opportunity to address these challenges. Africa is endowed with sufficient solar radiation potential that can be effectively harnessed as renewable energy resource. Consequently, this is favoured by her location which is within $37^{\circ} 21^{\prime} \mathrm{N}$ and $34^{\circ} 51^{\prime} 15^{\prime \prime S} \mathrm{~S}$ latitudes. Many African countries have most of its land mass exposed to an average of 325 days per year of bright sunlight (Yansane et al, 2007), thus suggesting a clear indication of the potential usage of solar energy resource in Africa. Reports have shown that the usage of solar energy radiation in Africa is now receiving the attention it has always deserves (Irimisose, 2009; REMP, 2007). The global energy crisis has prompted the need to proffer effective and efficient ways of harnessing solar energy resources.
At present, many of the African countries are embarking on exploration of solar energy resources for power supply. Thus, country like Nigeria seeks a long-term solution to the energy crisis through the Renewable Energy Master Plan (REMP, 2007). Currently, the Libyan government seeks the application of solar energy to household appliance with the aim of minimizing cost of electrical appliances at household level. The governments of Germany and South Africa provided joint support to a solar stove pilot program that included a comparative field test under real-life conditions to determine the social acceptance of solar stoves, as well as testing the commercial dissemination of solar stoves (Erica and Marlett, 2002). Furthermore, Europe, Germany and China proposed partnership between some Africa countries with the plan to build solar panel factories with a positive step towards addressing energy challenges. Under these circumanstances, it is highly desirable that detailed information about the availability of solar radiation on horizontal surface is 
essential for the optimum design and study of solar energy conversion systems. Solar radiation data are available for most part of the world, but is not available for many countries in Africa which cannot afford the measurement equipment and techniques involved (Ahmad et al, 2004).

Solar resources are known to exhibit a high variability in space and time due to the influence of other climatic factors such as cloud cover. Therefore, solar resource modeling or mapping is one of the essential management tools for proper development, planning, maintenance scheduling and pricing of solar energy systems. For efficient conversion and utilization of solar energy, the solar engineer designing solar energy systems require an accurate and detailed short term and long-term knowledge of the solar radiation characteristics of the location in various forms such as models or maps for proper sizing of the solar energy systems (Sozen et al, 2004; Chendo, 2001; Oparaku, 2003). Solar radiation models or maps are therefore essential design-input parameter in the assessment of solar energy systems (Fadare, 2009). The unavailability of solar radiation measuring equipment and techniques in many African countries has limited the development of solar energy applications in the continent.

Therefore, it is rather important to develop method to estimate the global and diffuse solar radiation based on other climatological parameters that are easily measured with more available equipment. To this effect, several empirical formulas have been developed to calculate the global solar radiation using various parameters. Previous studies in this area have been focused on the development of empirical models based parameters which include: sunshine hours (Glover and McCulloch, 1958), declination angle and latitude (Liu and Jordan, 1960), number of rainy days, sunshine hours, latitude and locations (Reddy, 1971), sunshine duration, relative humidity, maximum temperature, latitude, altitude and location (Sabbagh et al, 1977). Other studies in this area include the works of Ahmad et al, 2004; Abdullah and Farugh 1988; Chandal et al, 2005; Udo, 2002; Togrul and Onat, 2002. All these developed empirical models are location specific and hence are limited in scope and application.

Artificial neural network (ANN) modeling technique offers a better solution for developing a more generalized model for prediction of solar radiation data using climatological parameters. ANN is a modeling and prediction tool, widely accepted as a technique offering an alternative way to tackle complex and ill-defined problems (Kalogirou, 2001). They can learn from examples, are fault tolerant in the sense that they are able to handle noisy and incomplete data, to deal with non-linear problems and, once trained, can perform prediction and generalization at high speed. They have been used in diverse applications in control, robotics, pattern recognition, forecasting, medicine, power systems, manufacturing, optimization, signal processing and social/ psychological sciences. They are particularly useful in system modeling such as in implementing complex mappings and system identification (Kalogirou, 2000). ANN has been applied to modeling of complex systems such as meteorological parameters (Kalogirou, 2001; Kalogirou et al, 1998). Jiya and Alfa (2002) and Fadare (2009) have applied ANN model to model and predict solar radiation in Nigeria while Sozen et al. (2004) used the technique for mapping solar potential in Turkey. ANN models are efficient and less time consuming in modeling of complex systems compared to other mathematical models such as regression (Lin et al, 2003). ANN with different topologies has been developed for spatial prediction of wind speed in different parts of the world (Cellura et al, 2008, Kariniotakis et al, 1996; Fadare, 2010). Comprehensive reviews on ANN applications in renewable energy systems have been reported by Kalogirou, (2000; 2001). Basic theory and application of ANN can be found in generic text like (Picton, 2000). ANN models are known to be efficient and less time-consuming in modeling of complex systems compared to other mathematical models such as multiple regression (Kaldellis et al, 2009 and Adekoya and Adewale, 1992; Agbaka, 1987).

The aim of this study was to develop forward, backpropagation, multilayer preceptor neural network to predict the mean monthly global solar radiation in Africa. The essence of the study was to develop a cheap alternative model that can predict the monthly mean solar radiation potential for specific locations in Africa where there are no records of solar radiation.

\section{MATERIALS AND METHOD}

Model description: ANN is a branch of artificial intelligence $(\mathrm{Al})$, which belongs to the group of computational algorithms called connectionist models (Ojosu et al, 1990). ANN models are inspired by the biological neural system, with capability to learn, store and recall information based on a given training dataset. They are 'black-box' modeling technique capable of performing non-linear mapping of a 
multidimensional input space onto another multidimensional output space without the knowledge of the dynamics of the relationship between the input and output spaces. ANN-based models have been successfully employed in solving complex problems in various fields of application including pattern recognition, identification, classification, speech, vision, and control systems. In recent times, application of ANN models is becoming increasingly popular in many fields of engineering.

Basically, ANN models consist of multiple connected processing elements (PE), which are called nodes or neurons. They consist generally of five basic components: (1) input, (2) weight and biases, (3) summing junction, (4) transfer function, and (5) output. The neurons are arranged in three multiple layers known as input, hidden, and output layer. In neural networks, knowledge is acquired during the training or learning process by updating or adjusting the weights in the network through different algorithms. The network weights are upgraded literarily until the network reproduces the desired output or target from a given set of input. The network is trained with either supervised learning (when both input and the desired targets are presented to the network) or unsupervised learning (when the expected targets are not used in the training). The back-propagation algorithm is a supervised training rule with multiple-layer networks, in which the network weights are moved along the negative of the gradient of the mean squared error (MSE) so as to minimize the difference between the network's output and the desired target. There are generally four steps in the training process: (1) assembling the training data, (2) designing the network object, (3) training the network, and (4) simulating the network response with new input data sets. After a sufficient training session, which may require considerable computational resources such as memory and time of the computer, the trained network has adequate capabilities to perform nonlinear pattern association between input and output variables and can easily predict the output when a new input data set that is not used in the training is presented to the network.

Data Collection: Geographical and meteorological data of 172 locations in Africa for the period of 22 years (1983-2005) were obtained from NASA geosatellite database. The data includes geographical parameters: latitude (positive symbol $[+]$ indicates Northern region and negative symbol $[-]$ indicates Southern region), longitude (positive symbol [+] indicates Eastern region and negative symbol [-] indicates Western region), altitude, month of the year, and mean monthly meteorological parameters (sunshine duration, temperature, and relative humidity, and solar radiation intensity). Figure 1shows the geographical locations of the 172 locations in Africa used for the training (114 locations) and testing (58 locations) of the model. Tables 1 and 2 show the detailed geographical parameters of 114 locations used for training and 58 locations used for testing the model, respectively.

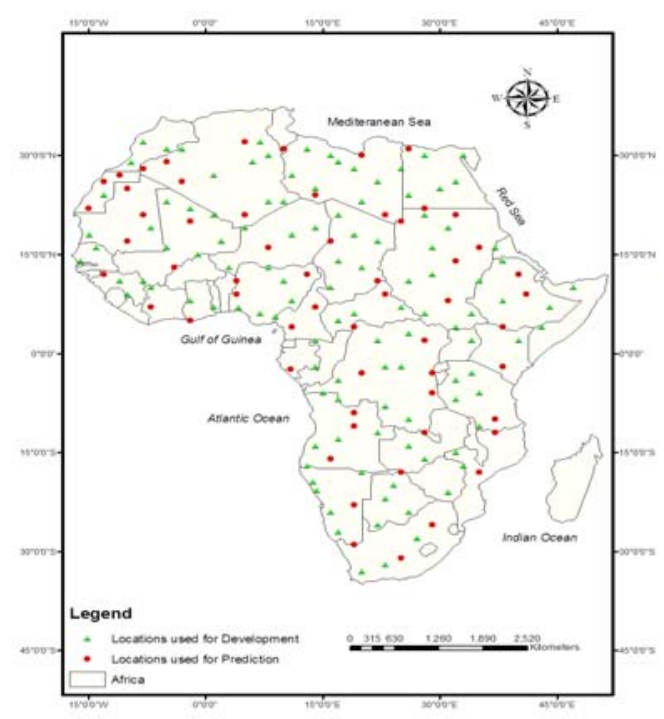

Fig 1: Geographical locations used for the development of the model 
Am. J. Sci. Ind. Res., 2010, 1(2): 144-157

Table 1: Geographical location of the 114 sites within Africa used for training, validation and testing of the neural network model

\begin{tabular}{|c|c|c|c|c|c|c|c|c|c|c|c|}
\hline \\
\hline S/No & LAT & LONG & ELVN & S/No & LAT & LONG & ELVN & S/No & LAT & LONG & ELVN \\
\hline 1 & 21 & 1 & 412 & 39 & 18 & 19 & 374 & 77 & 4 & 32 & 936 \\
\hline 2 & 22 & -2 & 333 & 40 & 17 & 22 & 896 & 78 & 1.5 & 34 & 1515 \\
\hline 3 & 23 & -5 & 301 & 41 & 16 & 29 & 424 & 79 & 2 & 40 & 411 \\
\hline 4 & 24 & -13 & 355 & 42 & 18.5 & 31 & 311 & 80 & 4 & 43 & 465 \\
\hline 5 & 25 & 14 & 516 & 43 & 16 & 36.5 & 489 & 81 & -2 & 14 & 576 \\
\hline 6 & 25 & 30 & 229 & 44 & 14 & -15.5 & 36 & 82 & -4 & 17 & 334 \\
\hline 7 & 26 & 22 & 184 & 45 & 11 & -11 & 466 & 83 & -1.5 & 22.5 & 448 \\
\hline 8 & 26 & 31.5 & 258 & 46 & 10.5 & -8 & 398 & 84 & -1.5 & 25 & 481 \\
\hline 9 & 26.5 & 1 & 18.5 & 47 & 14.5 & -1 & 278 & 85 & -4 & 31.5 & 1227 \\
\hline 10 & 27 & 11 & 531 & 48 & 12.5 & 2.5 & 241 & 86 & -3 & 34 & 1425 \\
\hline 11 & 27.5 & 19 & 228 & 49 & 13 & 8 & 436 & 87 & -6 & 15 & 684 \\
\hline 12 & 28 & 25 & 123 & 50 & 10.5 & 10 & 447 & 88 & -7 & 17 & 820 \\
\hline 13 & 28.5 & 17 & 285 & 51 & 14 & 17 & 292 & 89 & -8 & 23 & 891 \\
\hline 14 & 29 & 6 & 292 & 52 & 12.5 & 20 & 461 & 90 & -9.5 & 26 & 1126 \\
\hline 15 & 29.5 & 8 & 347 & 53 & 10.5 & 26 & 459 & 91 & -7 & 32 & 1162 \\
\hline 16 & 30 & 16 & 186 & 54 & 12 & 29 & 622 & 92 & -6 & 35 & 1153 \\
\hline 17 & 30 & 28 & 58 & 55 & 11 & 35 & 744 & 93 & -14 & 14 & 1356 \\
\hline 18 & 30 & 33 & 312 & 56 & 14 & 38 & 1629 & 94 & -13 & 16.5 & 1682 \\
\hline 19 & 30.5 & 13 & 465 & 57 & 9 & -10 & 550 & 95 & -12 & 22 & 1160 \\
\hline 20 & 30.5 & -3 & 576 & 58 & 10 & -7 & 366 & 96 & -14 & 26 & 1239 \\
\hline 21 & 32 & -8 & 438 & 59 & 8 & -2 & 140 & 97 & -14.5 & 32 & 857 \\
\hline 22 & 32 & 7 & 134 & 60 & 7 & 1 & 174 & 98 & -10.5 & 35 & 972 \\
\hline 23 & 31 & -5 & 953 & 61 & 6 & 7 & 186 & 99 & -19 & 11 & 2 \\
\hline 24 & 31 & -10 & 344 & 62 & 8 & 11 & 568 & 100 & -17 & 13 & 1105 \\
\hline 25 & 23 & 7.5 & 1261 & 63 & 9.5 & 16 & 369 & 101 & -18 & 20 & 1089 \\
\hline 26 & 22.5 & 9.5 & 707 & 64 & 5.5 & 19 & 453 & 102 & -19.5 & 23.5 & 937 \\
\hline 27 & 20.5 & 17 & 1460 & 65 & 7 & 25 & 732 & 103 & -16 & 27.5 & 1031 \\
\hline 28 & 23 & 19.5 & 708 & 66 & 6 & 28 & 499 & 104 & -17 & 32.5 & 563 \\
\hline 29 & 24 & 26 & 660 & 67 & 5.5 & 34 & 700 & 105 & -21 & 13.5 & 233 \\
\hline 30 & 20.5 & 28 & 390 & 68 & 8 & 38 & 2221 & 106 & -24 & 16 & 1557 \\
\hline 31 & 18 & -15.5 & 19 & 69 & 7 & 44 & 884 & 107 & -22 & 23 & 972 \\
\hline 32 & 16 & -14 & 54 & 70 & 9.5 & 47 & 883 & 108 & -24 & 26 & 977 \\
\hline 33 & 19 & -7 & 314 & 71 & 4 & 4 & 0 & 109 & -20.5 & 30.5 & 859 \\
\hline 34 & 15.5 & -5 & 269 & 72 & 4 & 8 & 55 & 110 & -27 & 17 & 1020 \\
\hline 35 & 17 & 2 & 469 & 73 & 2 & 13.5 & 584 & 111 & -26 & 22 & 1004 \\
\hline 36 & 18.5 & 5 & 453 & 74 & 4.5 & 16.5 & 575 & 112 & -28 & 26.5 & 1368 \\
\hline 37 & 17.5 & 11 & 461 & 75 & 1.5 & 22 & 422 & 113 & -33 & 20 & 1135 \\
\hline 38 & 19 & 14 & 443 & 76 & 3 & 26 & 621 & 114 & -32 & 23 & 1307 \\
\hline
\end{tabular}


Table 2: The 58 geographical locations in Africa used for prediction of solar energy potential

\begin{tabular}{|c|c|c|c|c|c|c|c|}
\hline S/No & LAT & LONG & ELVN & S/No & LAT & LONG & ELVN \\
\hline 1 & 20.5 & -8.0 & 313 & 30 & 7.0 & -7.0 & 366 \\
\hline 2 & 22.0 & -15.0 & 301 & 31 & 9.0 & 4.0 & 192 \\
\hline 3 & 24.5 & -10.0 & 277 & 32 & 7.0 & 13.5 & 932 \\
\hline 4 & 25.5 & -3.0 & 313 & 33 & 8.5 & 23.0 & 849 \\
\hline 5 & 26.0 & -13.0 & 222 & 34 & 7.5 & 31.0 & 402 \\
\hline 6 & 27.0 & -11.0 & 414 & 35 & 9.0 & 41.0 & 1433 \\
\hline 7 & 28.0 & -8.0 & 492 & 36 & 5.0 & -2.0 & 111 \\
\hline 8 & 29.0 & -5.0 & 568 & 37 & 4.0 & 10.5 & 241 \\
\hline 9 & 30.0 & 20.0 & 40 & 38 & 4.0 & 19.0 & 539 \\
\hline 10 & 30.5 & 10.0 & 452 & 39 & 2.0 & 28.0 & 859 \\
\hline 11 & 32.0 & 5.0 & 197 & 40 & 3.5 & 38.0 & 835 \\
\hline 12 & 31.0 & 26.0 & 75 & 41 & -3.0 & 10.0 & 100 \\
\hline 13 & 21.0 & 5.0 & 677 & 42 & -2.5 & 20.0 & 424 \\
\hline 14 & 24.0 & 13.5 & 642 & 43 & -3.0 & 29.0 & 1722 \\
\hline 15 & 21.0 & 23.0 & 559 & 44 & -2.0 & 38.0 & 630 \\
\hline 16 & 20.5 & 32.0 & 439 & 45 & -9.0 & 19.0 & 1091 \\
\hline 17 & 17.0 & -10.0 & 221 & 46 & -5.5 & 29.0 & 902 \\
\hline 18 & 19.5 & -2.0 & 283 & 47 & -9.5 & 36.5 .0 & 616 \\
\hline 19 & 16.0 & 7.5 .0 & 456 & 48 & -11.0 & 19.0 & 1265 \\
\hline 20 & 16.5 & 16.0 & 258 & 49 & -11.5 & 28.0 & 1162 \\
\hline 21 & 19.5 & 25.0 & 585 & 50 & -12.0 & 37.0 & 458 \\
\hline 22 & 15.5 & 35.0 & 454 & 51 & -16.0 & 16.0 & 1304 \\
\hline 23 & 12.0 & -13.0 & 233 & 52 & -17.5 & 25.0 & 977 \\
\hline 24 & 13.0 & -4.0 & 278 & 53 & -18.0 & 35.0 & 153 \\
\hline 25 & 11.0 & 4.0 & 220 & 54 & -23.0 & 19.0 & 1401 \\
\hline 26 & 12.0 & 13.0 & 287 & 55 & 21.5 & 28.0 & 840 \\
\hline 27 & 11.0 & 22.0 & 573 & 56 & -29.0 & 19.0 & 755 \\
\hline 28 & 13.5 & 32.0 & 390 & 57 & -25.5 & 29.0 & 1469 \\
\hline 29 & 11.5 & 40.0 & 720 & 58 & -31.0 & 25.0 & 1397 \\
\hline
\end{tabular}

Design of the artificial neural network model: Multi-layer feed-forward back-propagation hierarchical networks with different architecture were designed using the NeuroSolutions ${ }^{\circledR}$ version 5.0. The networks consist of three layers: input layer; hidden layer; and output layer. A typical three layered ANN is shown in Figure 2. There were seven input parameters into the network, which consisted of the geographical and meteorological parameters of the locations and one output parameter corresponding to the global solar radiation intensity. Different networks with single or double hidden layer topologies were used and the number of neurons was varied from 5 to 15 , at interval of five neurons. No transfer function was used in the neurons in the input layer, while neurons with tangent sigmoid (tansig) and linear (purelin) transfer functions were used in the hidden layer(s) and output layer, respectively. 


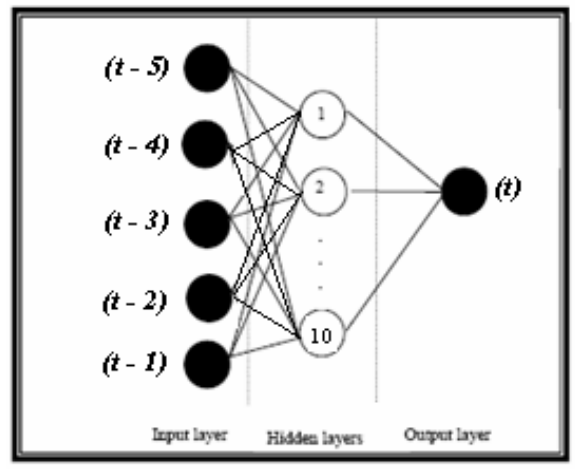

Fig. 2: Typical structure of a MLP neural network

Training and testing of the model: Prior to the training process, both input and target data sets were normalized to range -1 and +1 . Scaled conjugate gradient (SCG) and Levenberg-Marquardt (LM) learning algorithms were used for the training of the networks. In order to avoid 'over fitting' of the data and hence improve generalization of the network the 'early stopping' technique was used in conjunction with the training algorithms. The input/target dataset was divided randomly into three subsets: training; validation; and testing datasets. The training set, which consists of $50 \%$ of the dataset, was used for computing the gradient and updating the network weights and biases, while $25 \%$ of the dataset was used as validation and test dataset respectively for each network. The maximum number of 3000 epochs was used in the training process. The networks were tested 35 times using different randomly selected weights and biases. The different network structures were trained using dataset of the 114 locations and their predictive performance were evaluated based on the Mean Square Error (MSE) and Cross Validation Mean Square Error (CV MSE) between the predicted and the actual values in order to determine the network optimum structure required for best predictive performance.

\section{RESULTS AND DISCUSSION}

Network optimization: After sufficient training sessions, which required considerable computational resources in terms of memory and time of the computer, the networks were found to have considerable capabilities to perform non-linear pattern association between the input (geographical and meteorological parameters) and output (solar radiation). The network with single hidden layer of five neurons trained with Levenberg Marquardt learning algorithm was found to be the optimum network structure required for the model. Using the optimum network structure, the correlation between the predicted and the actual values of monthly mean solar radiation for January is shown graphically in Figure 3, while Table 3 shows the results of values of mean square error (MSE) and cross validation mean square error (CV MSE) obtained for the months of January to December. As shown in Table 3 the MSE values ranged between 0.002 and 0.004 , while CV MSE ranged between 0.03 and 0.053 , which implies that the ANN predicted solar radiation values are very close to the actual values.

Table 3: Values of MSE and CV MSE for each network model

\begin{tabular}{|l|c|c|}
\hline MONTH & MSE & CV MSE \\
\hline JANUARY & 0.002 & 0.045 \\
\hline FEBRUARY & 0.002 & 0.05 \\
\hline MARCH & 0.004 & 0.05 \\
\hline APRIL & 0.003 & 0.03 \\
\hline MAY & 0.003 & 0.043 \\
\hline JUNE & 0.002 & 0.04 \\
\hline JULY & 0.003 & 0.04 \\
\hline AUGUST & 0.003 & 0.053 \\
\hline SEPTEMBER & 0.003 & 0.035 \\
\hline OCTOBER & 0.002 & 0.04 \\
\hline NOVEMBER & 0.004 & 0.054 \\
\hline DECEMBER & 0.003 & 0.039 \\
\hline
\end{tabular}

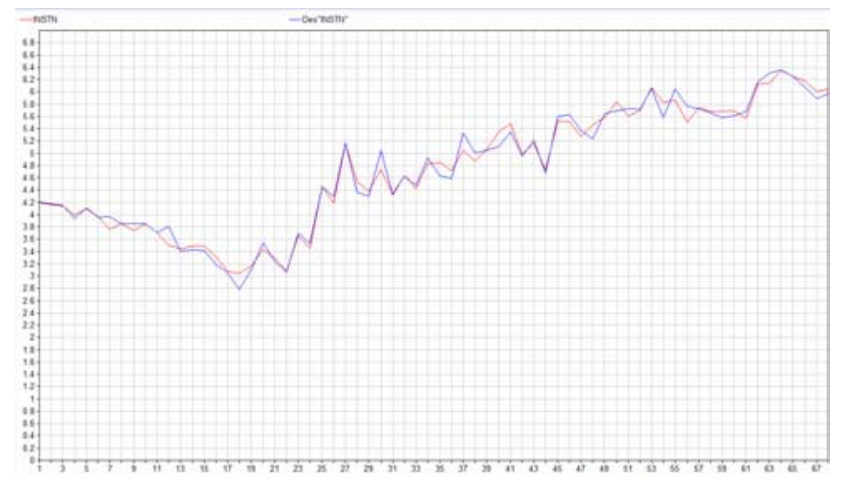

Fig. 3: Comparison between the ANN predicted and actual solar radiation for the month of January in Africa

Prediction of solar radiation potential in Africa: After the network has been trained with sufficient accuracy, the model was used to predict the monthly mean solar radiation potential for other 58 locations spread over Africa that were not used in the training of the model. The actual and the ANN predicted 
monthly mean solar radiation values for the 58 locations for the months of January to December were presented in the form of monthly maps in Figures 4 to 15 using the Geographical Information System (GIS) software ArcVeiw ${ }^{\circledR}$ 3.2. Figures 4- 15 (a) show the actual solar radiation maps, Figures 4. 15 (b) show the ANN predicted solar radiation maps. It can be seen that the ANN predictions are very close to the actual solar radiation values. It can also be observed that the trend of the contour lines showed that from April - September the solar energy potential was higher in the northern hemisphere, which is the region of Africa above the equator. The solar energy potential over Northern Africa within these periods ranged between 5.0 and $7.5 \mathrm{~kW}$ $\mathrm{h} / \mathrm{m}^{2} /$ day (Figures $7-12$ ). These periods correspond to the wet season when the sun is directly overhead the northern region of Africa, thus, causing intense solar radiation. The Sahara desert is also located in this area, the low amount of cloud-cover over the desert also make the condition of higher solar energy potential for the desert region possible. Southern Africa, which is the region below the equator, showed lower solar energy potential for the same period. The sun is at an oblique angle during this period and is never directly overhead the southern region of Africa.
This relative inclination of the southern region to sun radiation during this period thus affects the amount of solar energy reaching the region. Hence, lower values of solar radiation were observed in the southern region for these periods, which varied between 3.5 and $5.5 \mathrm{~kW} \mathrm{~h} / \mathrm{m}^{2} /$ day (Figures 7 - 12). However, the trend was reversed for the months of October to March. The solar energy potential for these periods was higher in the southern hemisphere of Africa compared to the north hemisphere. This corresponds to the period when the sun is almost directly overhead in southern region. For these periods, the solar energy potential for the southern region of Africa ranged between 5.5 and $7.5 \mathrm{~kW}$ $\mathrm{h} / \mathrm{m}^{2} /$ day (see Figures $4-6,13$ and 15 ). The Kalahari Desert, which covers most of Botswana and portions of northern South Africa and eastern Namibia and the Namib Desert, which stretches along the southwestern coast of Africa, from southern Angola along the entire length of Namibia, and into western South Africa, are typical areas with the highest solar radiation $\left(7.0-7.5 \mathrm{~kW} \mathrm{~h} / \mathrm{m}^{2} /\right.$ day $)$ for these periods. The solar radiation potential for the same period in the northern region of Africa were lower and ranged between 2.5 and $5.5 \mathrm{~kW} \mathrm{~h} / \mathrm{m}^{2} /$ day.

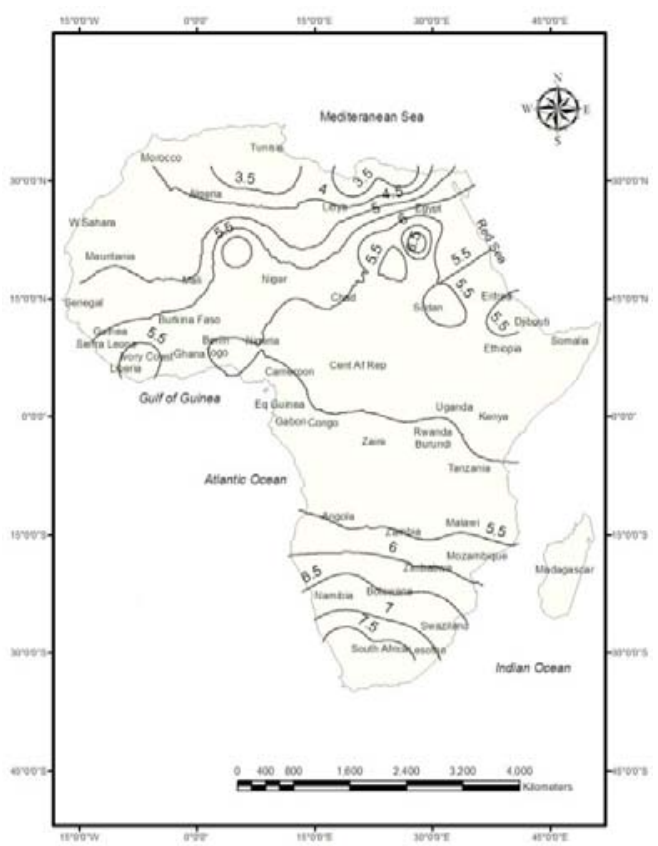

(b)

(a)

Fig.4: Actual (a) and ANN (b) predicted solar energy potential (kW h/m $/ 2$ day) for the month of January in Africa 


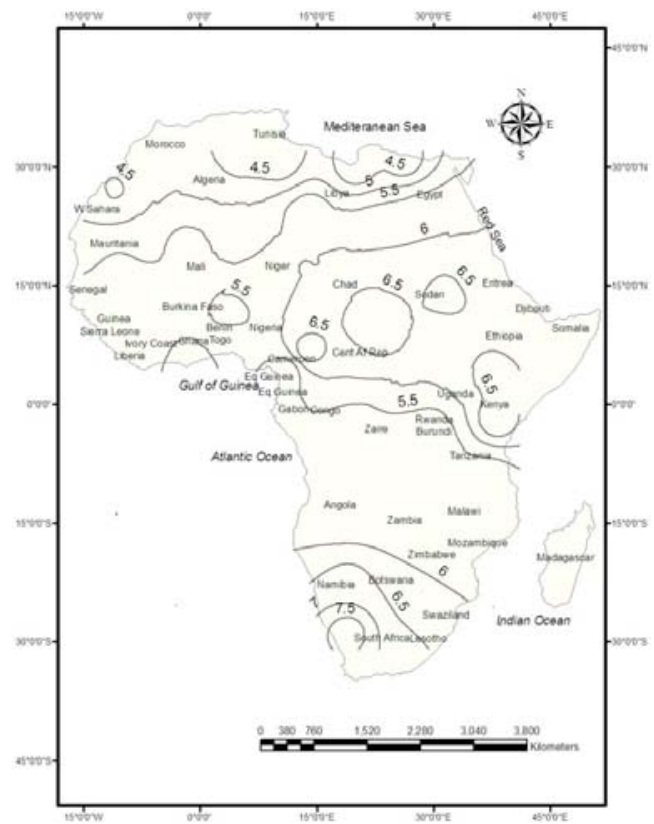

(a)

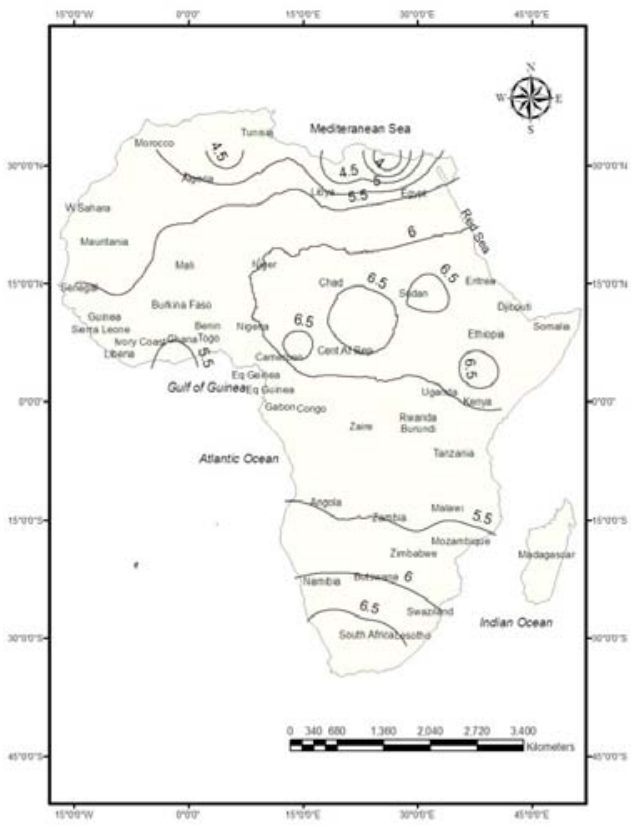

(b)

Fig. 5: Actual (a) and ANN (b) predicted solar energy potential ( $\mathrm{kW} \mathrm{h} / \mathrm{m}^{2} /$ day) for the month of February in Africa

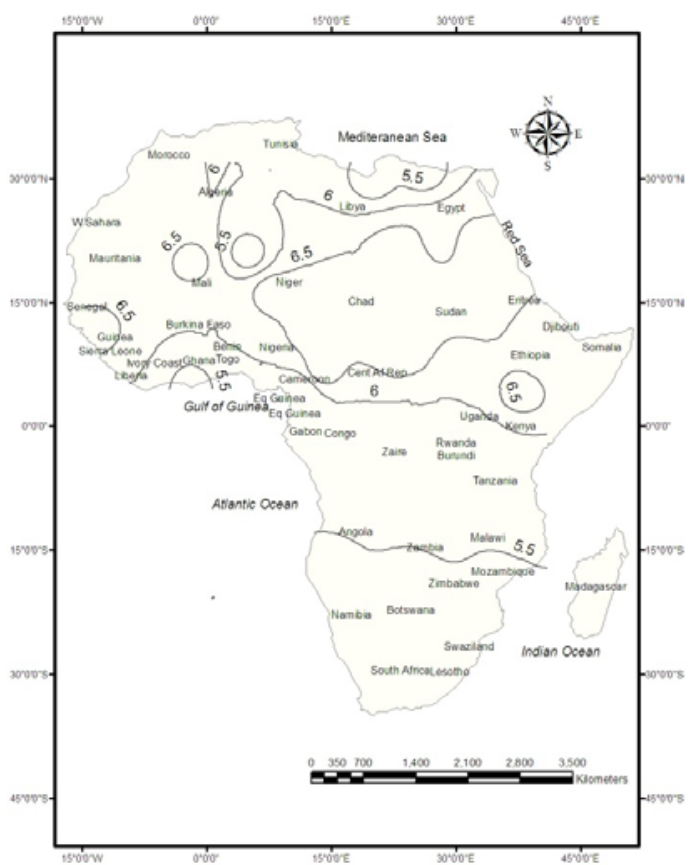

(a)

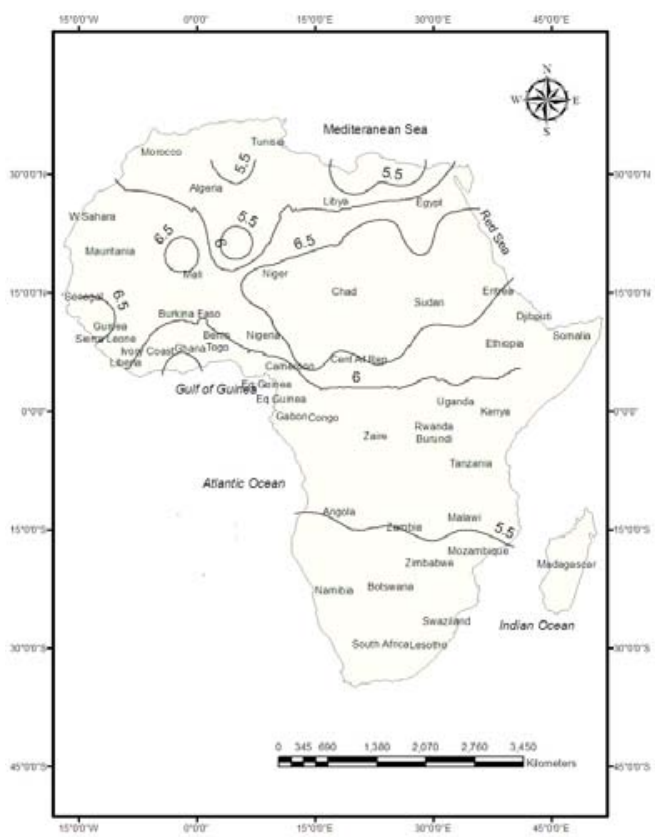

(b)

Fig. 6: Actual (a) and ANN (b) predicted solar energy potential ( $\left.\mathrm{kW} \mathrm{h} / \mathrm{m}^{2} / \mathrm{day}\right)$ for the month of March in Africa 
Am. J. Sci. Ind. Res., 2010, 1(2): 144-157

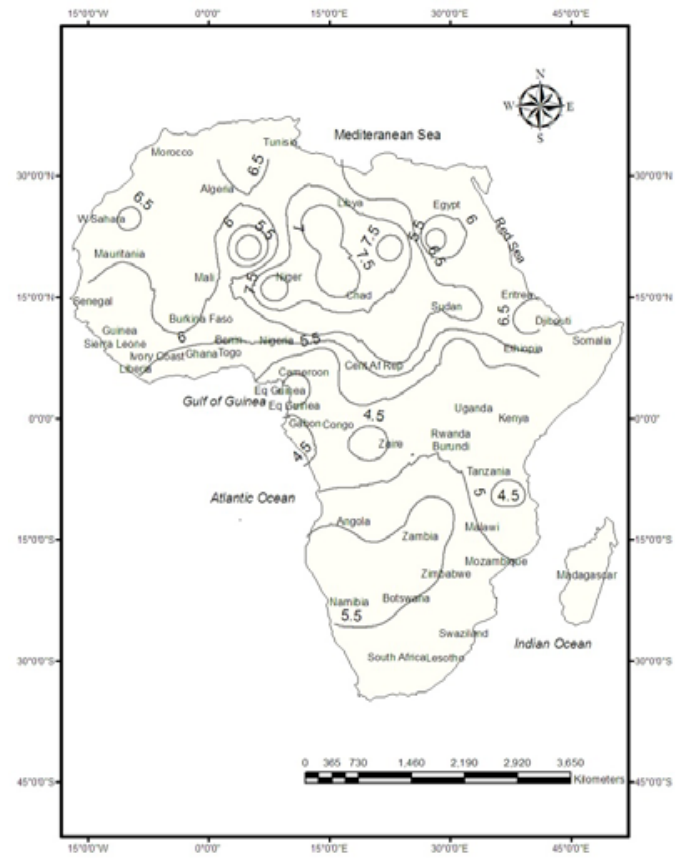

(a)

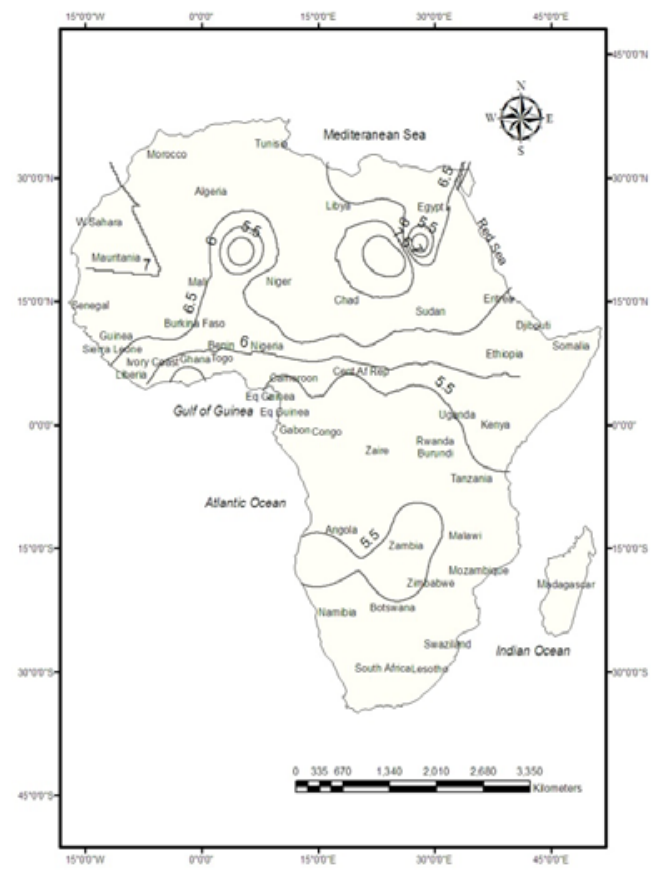

(b)

Fig. 7: Actual (a) and ANN (b) predicted solar energy potential ( $\mathrm{kW} \mathrm{h} / \mathrm{m}^{2} /$ day) for the month of April in Africa

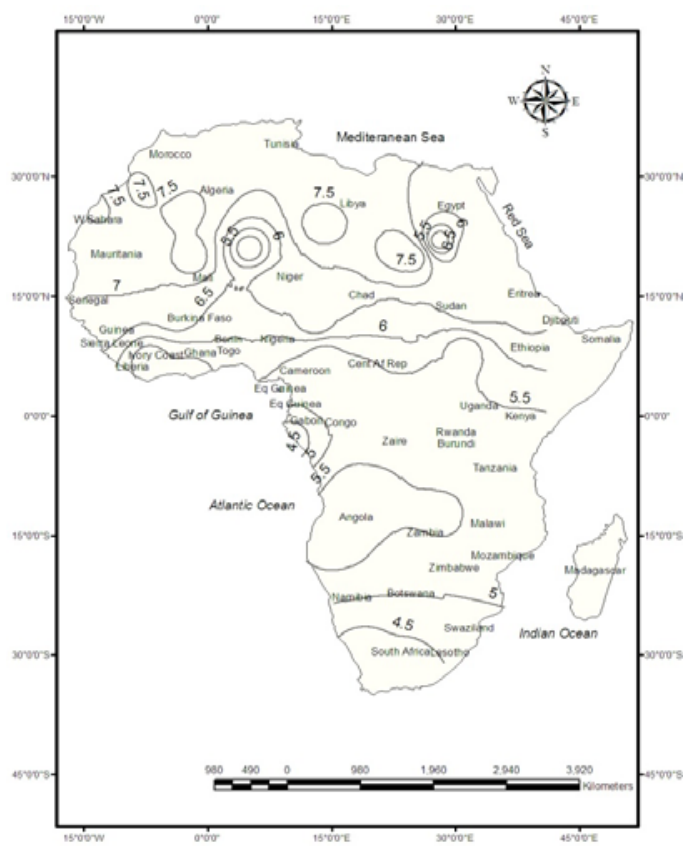

(a)

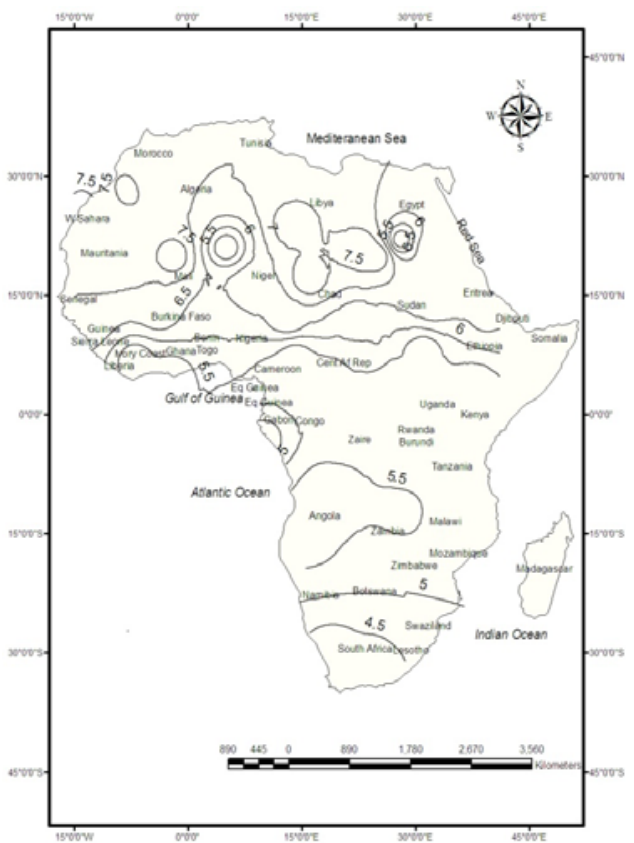

(b)

Fig. 8: Actual (a) and ANN (b) predicted solar energy potential ( $\mathrm{kW} \mathrm{h} / \mathrm{m}^{2} /$ day) for the month of May in Africa 


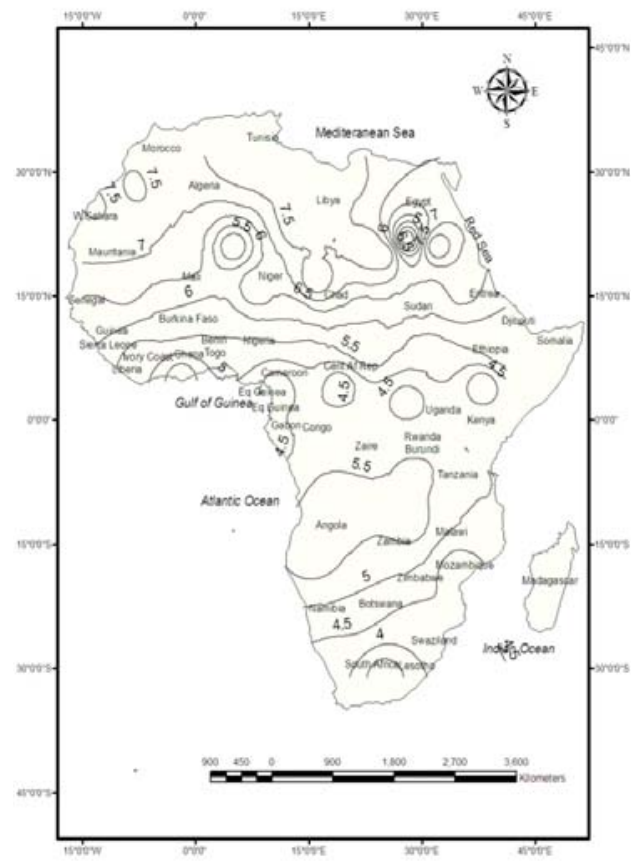

(a)

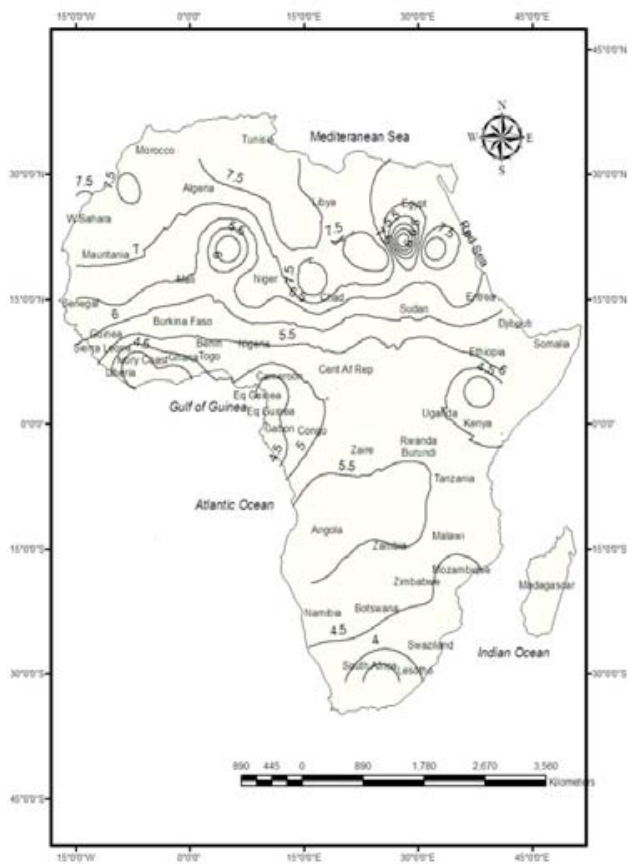

(b)

Fig. 9: Actual (a) and ANN (b) predicted solar energy potential ( $\mathrm{kW} \mathrm{h} / \mathrm{m}^{2} /$ day) for the month of June in Africa

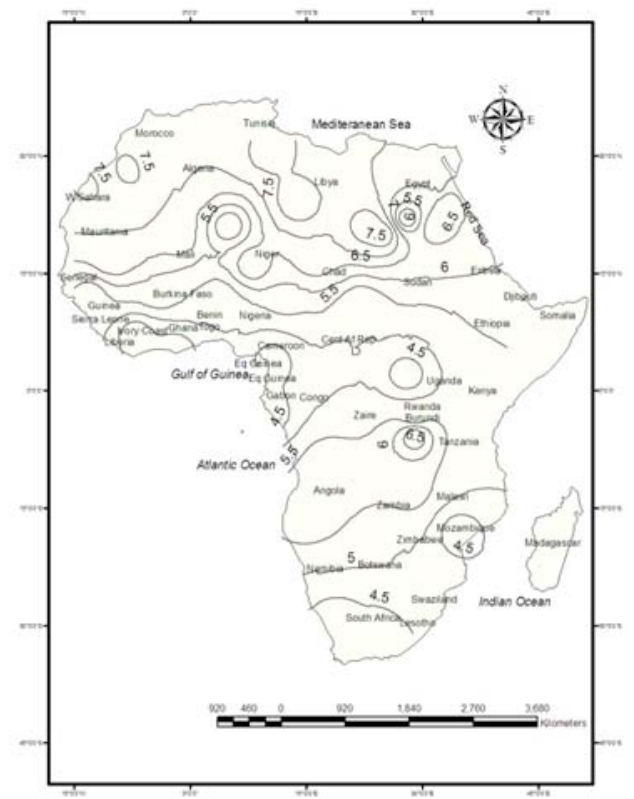

(a)

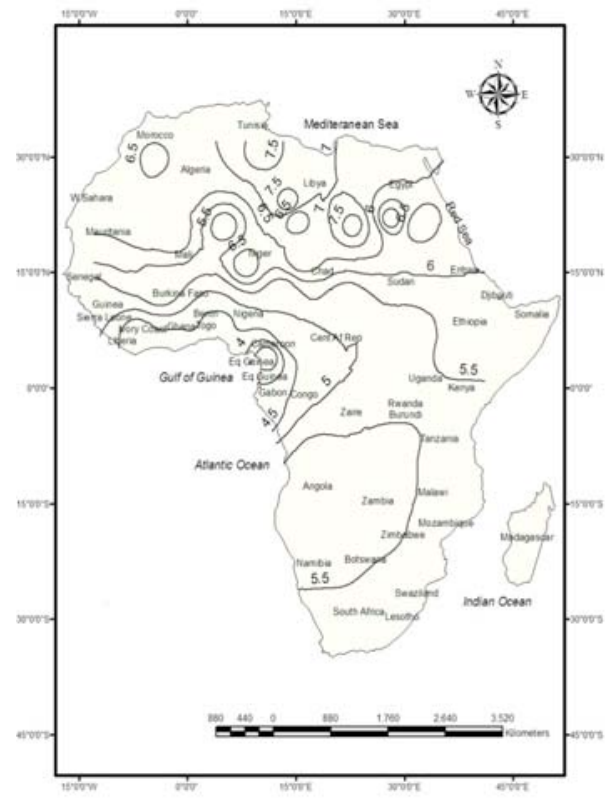

(b)

Fig. 10: Actual (a) and ANN (b) predicted solar energy potential ( $\mathrm{kW} \mathrm{h} / \mathrm{m}^{2} /$ day) for the month of July in Africa 
Am. J. Sci. Ind. Res., 2010, 1(2): 144-157

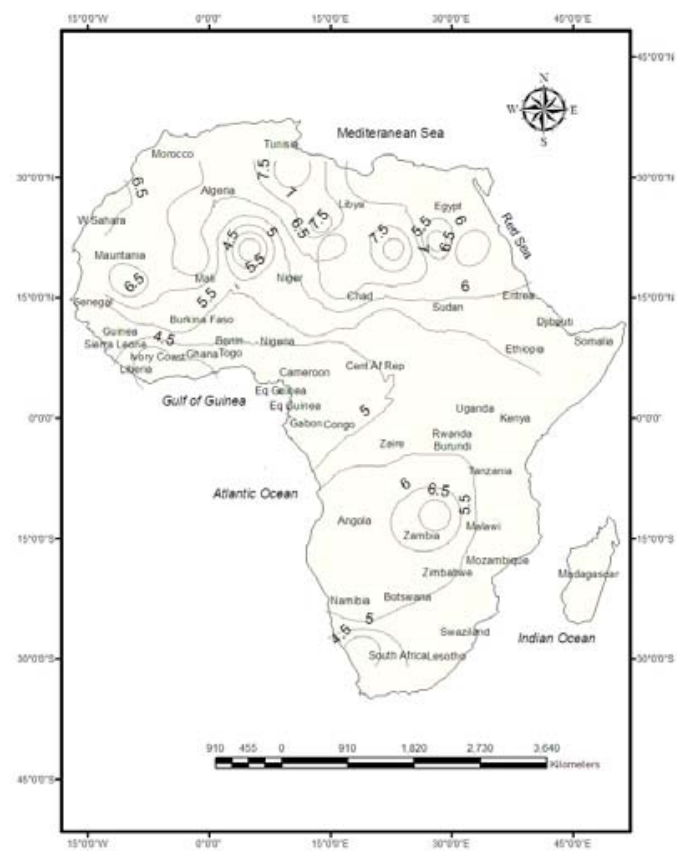

(a)

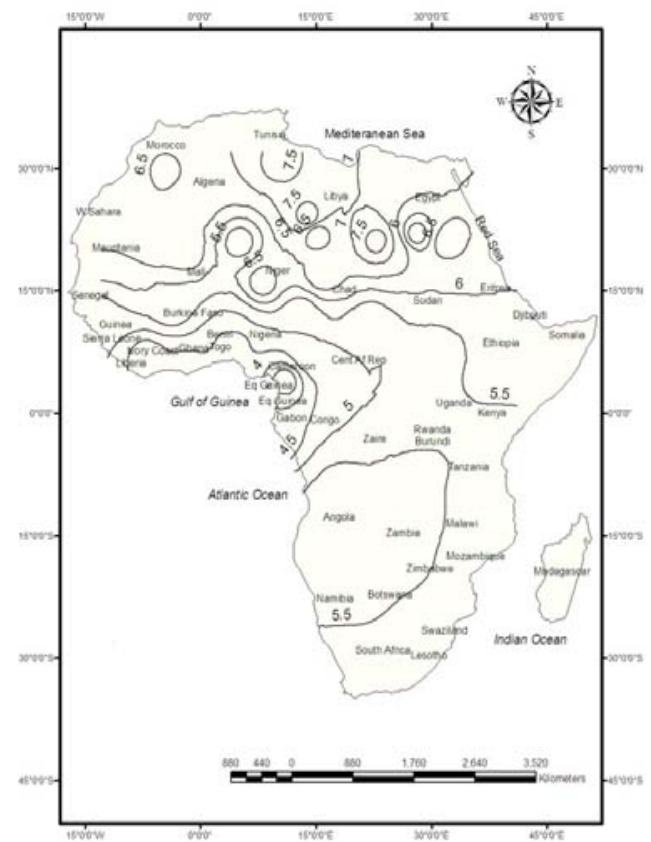

(b)

Fig. 11: Actual (a) and ANN (b) predicted solar energy potential (kW h/m $/ 2$ day) for the month of August in Africa

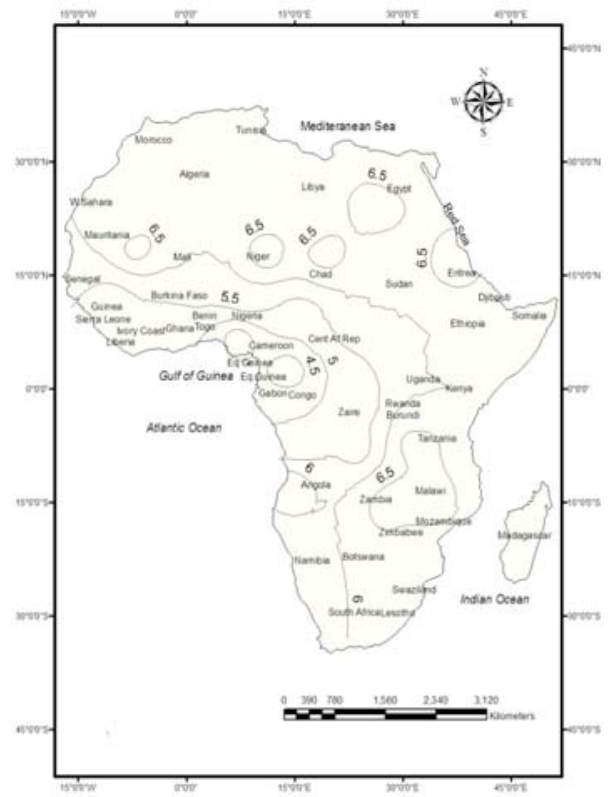

(a)

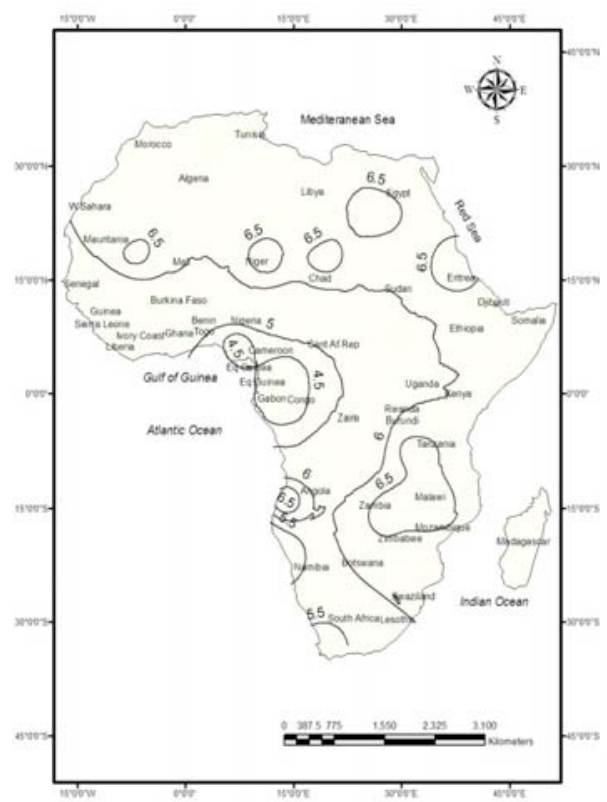

(b)

Fig. 12: Actual (a) and ANN (b) predicted solar energy potential ( $\mathrm{KWh} / \mathrm{m}^{2} /$ day) for the month of September in Africa 
Am. J. Sci. Ind. Res., 2010, 1(2): 144-157

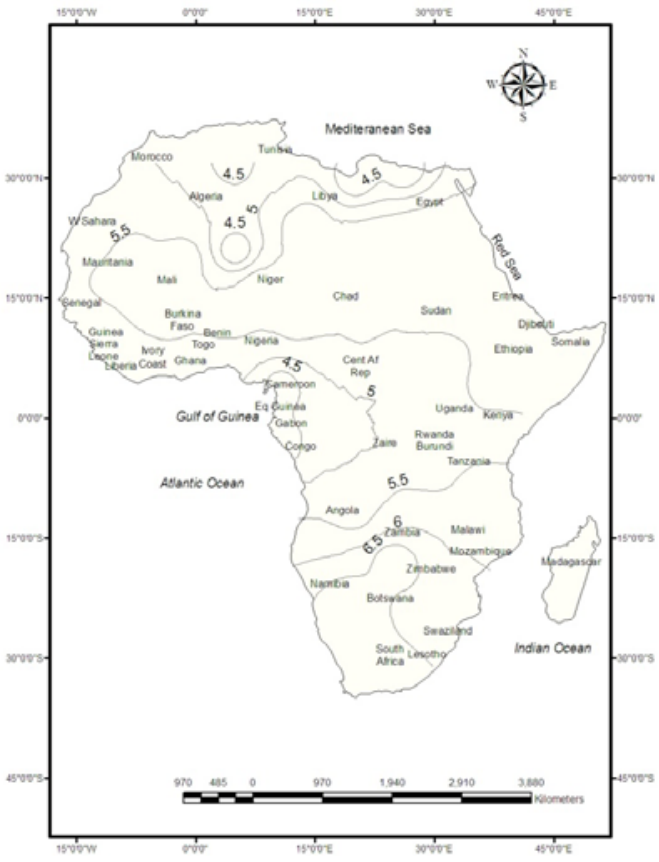

(a)

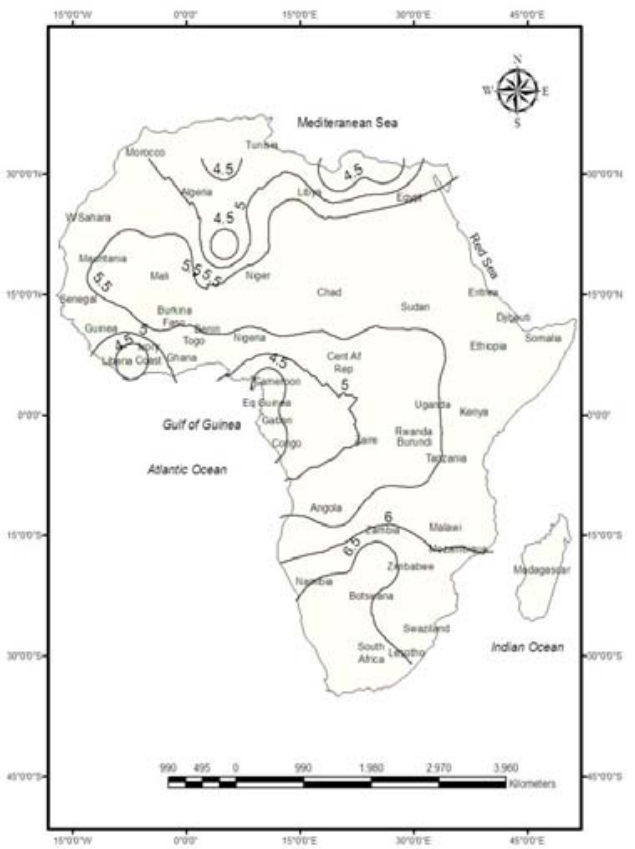

(b)

Fig.13: Actual (a) and ANN (b) predicted solar energy potential ( $\mathrm{kW} \mathrm{h} / \mathrm{m}^{2} /$ day) for the month of October in Africa

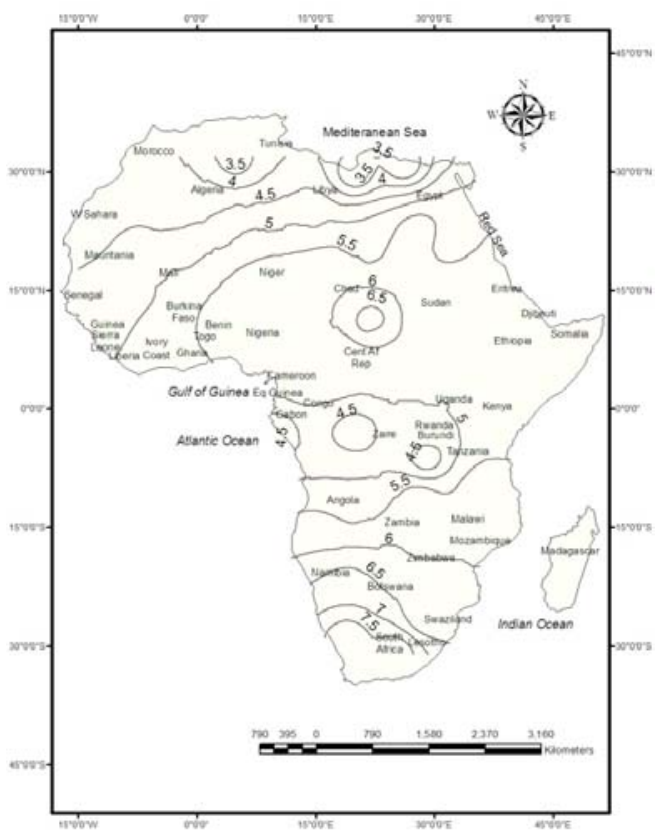

(a)

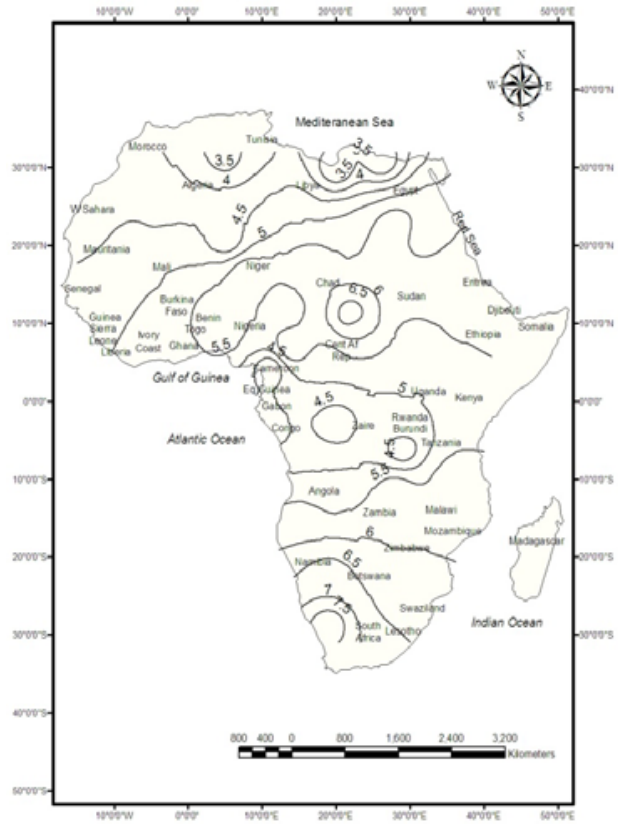

(b)

Fig. 14: Actual (a) and ANN (b) predicted solar energy potential ( $\mathrm{kW} \mathrm{h} / \mathrm{m}^{2} /$ day) for the month of November in Africa 
Am. J. Sci. Ind. Res., 2010, 1(2): 144-157

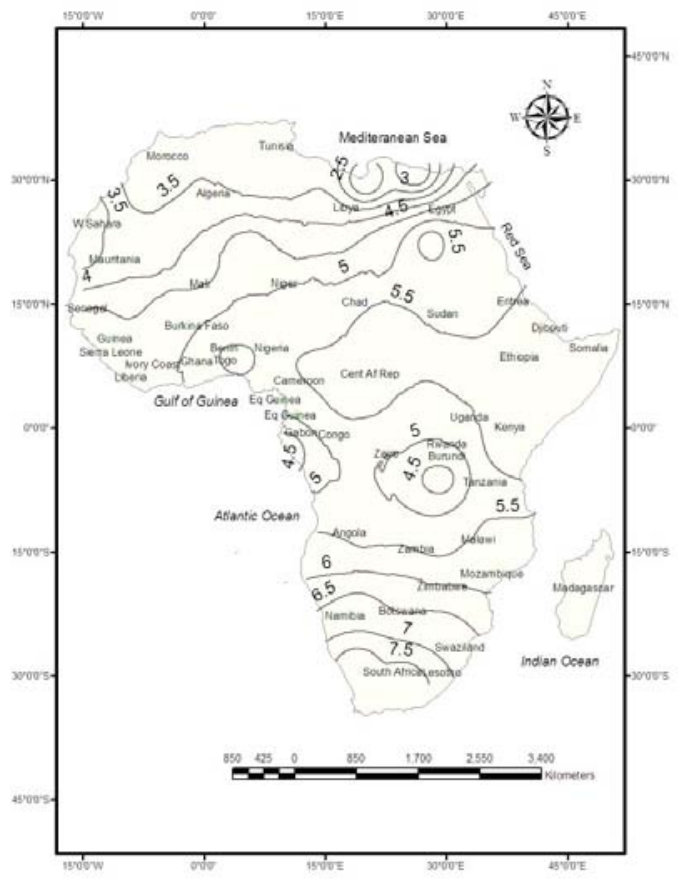

(a)

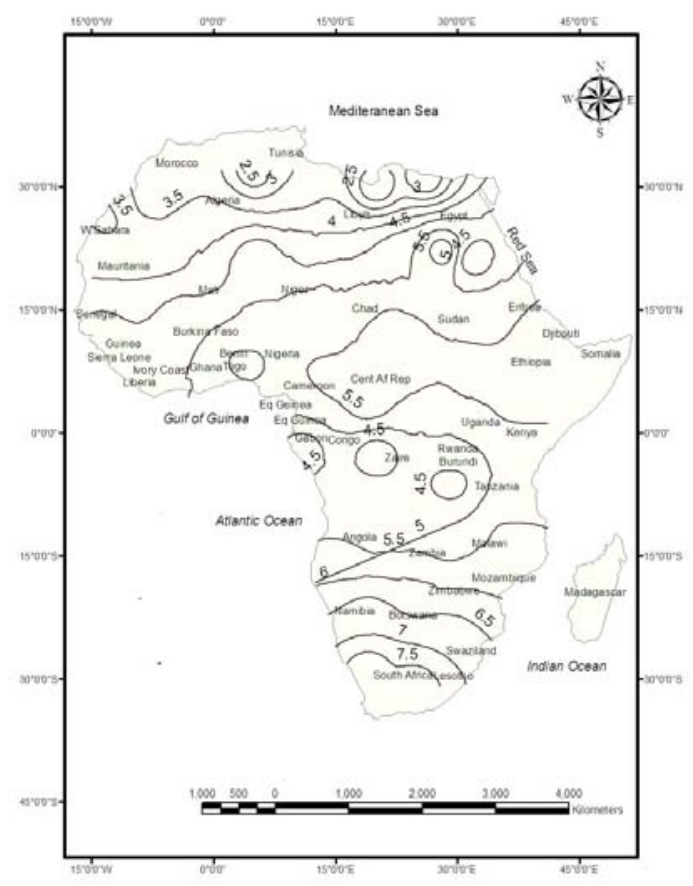

(b)

Fig 15: Actual (a) and ANN (b) predicted solar energy potential ( $\mathrm{kW} \mathrm{h} / \mathrm{m}^{2} /$ day) for the month of December in Africa

\section{CONCLUSION}

The comparison of the ANN predicted solar energy potential compared with the actual values showed negligible difference. Hence, the study confirms the ability of the ANN- based model for accurate modeling and prediction solar radiation data. The ANN model was capable of predicting accurately and therefore, can be used to predict solar radiation for any location without solar radiation data but provided that comprehensive meteorological data are available.

\section{REFERENCES}

Abdullah, Y.A.G. and Farugh G.M. (1988). Contribution to the study of solar radiation in Abu Dhabi. Energy Conversion and Management 28(1): 63-67.

Adekoya, L.O.and Adewale A.A. (1992). Wind energy potential of Nigeria. Renew Energy 2(1): 35-9.

Agbaka, A.C. (1987). Experimental investigation of the possible correction of wind speed on insolation. Energy Convers Management 27(1): 45-8.

Ahmad, F.and Ulfat, I. (2004). Empirical model for the correlation of monthly average daily global solar radiation with hours of sunshine on a horizontal surface at Karachi, Pakistan. Turkish J. Physics 28: 301-307.

Cellura, M., Cirrincione, G., Marvvuglia, A. and Miraoui. A. (2008). Wind speed spatial estimation for energy planning in Sicily: a neural Kriging application. Renew Energy 33(6):1251-66.

Chandal, S.S., Agarwal, R.K. and Pandey, A.N. (2005). New correlation to estimate global solar radiation on horizontal surface using sunshine hours and temperature data for Indian cities. Jour. of Solar Energy Engineering 127: 417-420.

Chendo, M.A.C. (2001). Non-conventional energy source: development, diffusion and impact on human development index in Nigeria, Nigeria J. Renew. Energy 9(1-2): 91-102.

Erica, L. and Marlett, W. (2002). Harnessing solar stove technologies in South Africa to promote improved household energy provision. Palmer Development Consulting.

Fadare D.A. (2010). The Application of artificial neural networks to mapping of wind speed profile for energy application in Nigeria. Applied Energy 87: 934-942.

Fadare, D.A. (2009). Modelling of Solar Energy Potential in Nigeria Using an Artificial Neural Network Model. Applied Energy 88: 1410-1422. 
Glover, J. and McCulloch, F. (1958). The empirical relationship between solar radiation and hours of sunshine. Q.J.R. Met. Soc. 84(359): 56-60.

Irimisose, I. (2009). Modelling of solar energy potential in Africa using artificial neural network.Unpublished B.Sc. project, University of Ibadan, Ibadan, Nigeria.

Jiya, J.D. and Alfa, B. (2002). Parametization of solar radiation using neural network. Nigerian J. Renew. Energy 10(1\&2): 6-10.

Kaldellis, J.K., Kavadias, K.A. and Filios, A.E. (2009). A new computational algorithm for the calculation of maximum wind energy penetration in autonomous electrical generation systems. Applied Energy 86(78):1011-23.

Kalogirou, S.A. (2000). Applications of artificial neural networks for energy systems. Applied Energy Reviews 67(1-2): 17-35.

Kalogirou, S.A. (2001). Artificial neural networks in renewable energy systems Applications: A Review. Renewable and Sustainable Energy Reviews 5(4): 373-401.

Kalogirou, S.A., Neocleous, C.C. and Schizas, C.N. (1998). Artificial neural networks for modelling the Start -up of a solar steam generator. Applied Energy 60:98-100.

Kariniotakis, G.N., Stavrakakis, G.S. and Nogaret E.F. (1996). Wind power forecasting using advanced neural networks models. Energy Convers, IEEE Trans 11(4):762-7.

Lin, T., Bhattacharyya, D. and Kecman V. (2003). Multiple regression and neural networks analyses in composites machining. Compos Sci. Technol. 63: 539-48.
Liu, Y.H. and Jordan, RC. (1960). The inter-relationship and characteristic distribution of direct, diffuse and total solar radiation from metrological data. Solar Energy 4: 1-19.

Ojosu, J.O. and Salawu, R.I. (1990). Wind energy development in Nigeria. Nigerian J. Sol. Energy 9: 2932.

Oparaku, O.U. (2003). Designed criteria of solar water pumping systems for agricultural production. Nigerian Journal of Solar Energy 14: 62-65.

Picton, P. (2000). Neural networks. 2nd ed. UK: Antony Rowe Ltd.

Reddy, S.J. (1971). An empirical method for the estimation of net radiation intensity. Solar Energy 13: 291-292.

REMP- Renewable Energy Master Plan (2007). Energy commission of Nigeria, Federal Ministry of Energy Resources, Nigeria

Sabbagh, J.A., Sayigh, A.A.M. and El-Salam, E.M.A. (1977). Estimation of the total solar radiation from meteorological data. Solar Energy 19: 307-311.

Sozen, A., Arcaklioglu, E., Ozalp, M. and Kanit, E.G. (2004). Use of Artificial neural Network for mapping of solar potential in Turkey. Applied Energy 77:273-86.

Togrul, I.T. and Onat, E. (2002). Global Solar Radiation over Turkey. Comparison of Predicted and Measured Data. Renewable Energy 25(1): 55-67.

Udo S.O. (2002). Contribution to the relationship between solar radiation and sunshine duration in the tropics: $A$ study case of experimental data at Ilorin, Nigeria. Turkish J. Physics 26: 229.

Yansane, A. (2007). Solar power in Africa. National Solar Power Research Institute. 